\title{
The loss of healthy life time is similarly high for both food allergy and intolerance sufferers
}

\author{
Andreas Arens-Volland ${ }^{1 *}$, Norbert Rösch², Sabine Schnadt ${ }^{3}$ \\ From Food Allergy and Anaphylaxis Meeting 2014 \\ Dublin, Ireland. 9-11 October 2014
}

\section{Background}

Little is known about the loss of productive workforce or healthy life time due to food allergy or food intolerance. One aim of the BELANA trial (Burdens and Expenses of Living as Adult with Nutrition based Allergy or Intolerance) was to investigate the healthy time lost for work or spare time due to corresponding disease.

\section{Methods}

314 study participants $(\geq 18)$ with self-reported food allergies or intolerances were recruited in 2009 by the German Allergy and Asthma Association (DAAB). 247 completed the BELANA questionnaire four times within four-month intervals. The participants had to state whether they were unable to fulfil their daily tasks at work, at home, or at school due to problems with their food allergy or intolerance. Furthermore, they had to indicate the number of affected days.

\section{Results}

About 43\% (average of all single surveys) of all selfreported food allergy and food intolerance suffers reported that they have missed at least one day of work or every day life during the past four months. About $37 \%$ of the participants stated to not have experienced such losses. Comparing the two subgroups of food allergic and food intolerant persons, no significant difference could be determined. Similarly, reviewing the actual number of days lost, people from both subgroups accounted for a noticeably high number of lost days: 15.68 days on average during the past four months. Figure 1 exemplarily shows the density distribution of lost workdays for the participants of the fourth iteration of the questionnaire.

${ }^{1}$ CRP Henri Tudor, Luxembourg, Luxembourg

Full list of author information is available at the end of the article

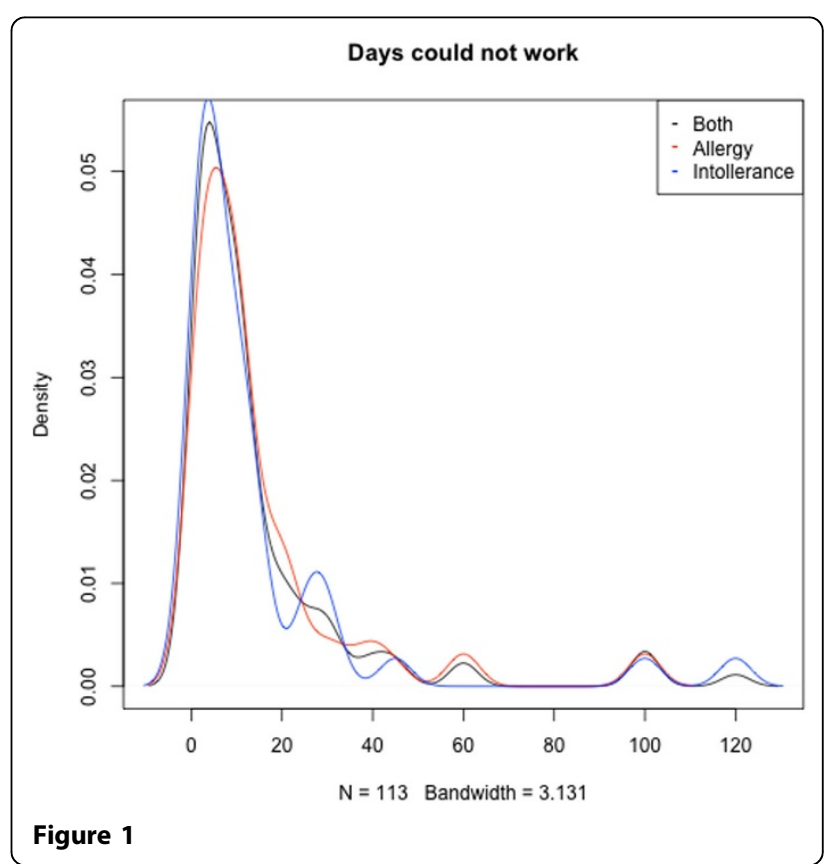

\section{Conclusion}

The group of self-reported food allergy and food intolerance sufferers that complain about the loss of healthy time due to their illness is larger as compared to the group that does not experience this kind of burden. The high number of lost healthy days indicates that the data might be biased towards severe cases of food allergy and intolerance. This will need further investigation through cross-validation with other questionnaire items.

\footnotetext{
Authors' details

${ }^{1}$ CRP Henri Tudor, Luxembourg, Luxembourg. ${ }^{2}$ University of Applied Sciences, Kaiserslautern, Germany. ${ }^{3}$ German Allergy and Asthma Association, Mönchengladbach, Germany.
}

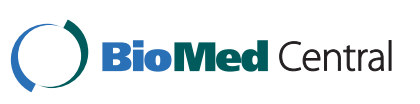

(c) 2015 Arens-Volland et al; licensee BioMed Central Ltd. This is an Open Access article distributed under the terms of the Creative Commons Attribution License (http://creativecommons.org/licenses/by/4.0), which permits unrestricted use, distribution, and reproduction in any medium, provided the original work is properly cited. The Creative Commons Public Domain Dedication waiver (http://creativecommons.org/publicdomain/zero/1.0/) applies to the data made available in this article, unless otherwise stated. 
- Convenient online submission

- Thorough peer review

- No space constraints or color figure charges

- Immediate publication on acceptance

- Inclusion in PubMed, CAS, Scopus and Google Scholar

- Research which is freely available for redistribution 